Provided for non-commercial research and educational use only. Not for reproduction or distribution or commercial use.
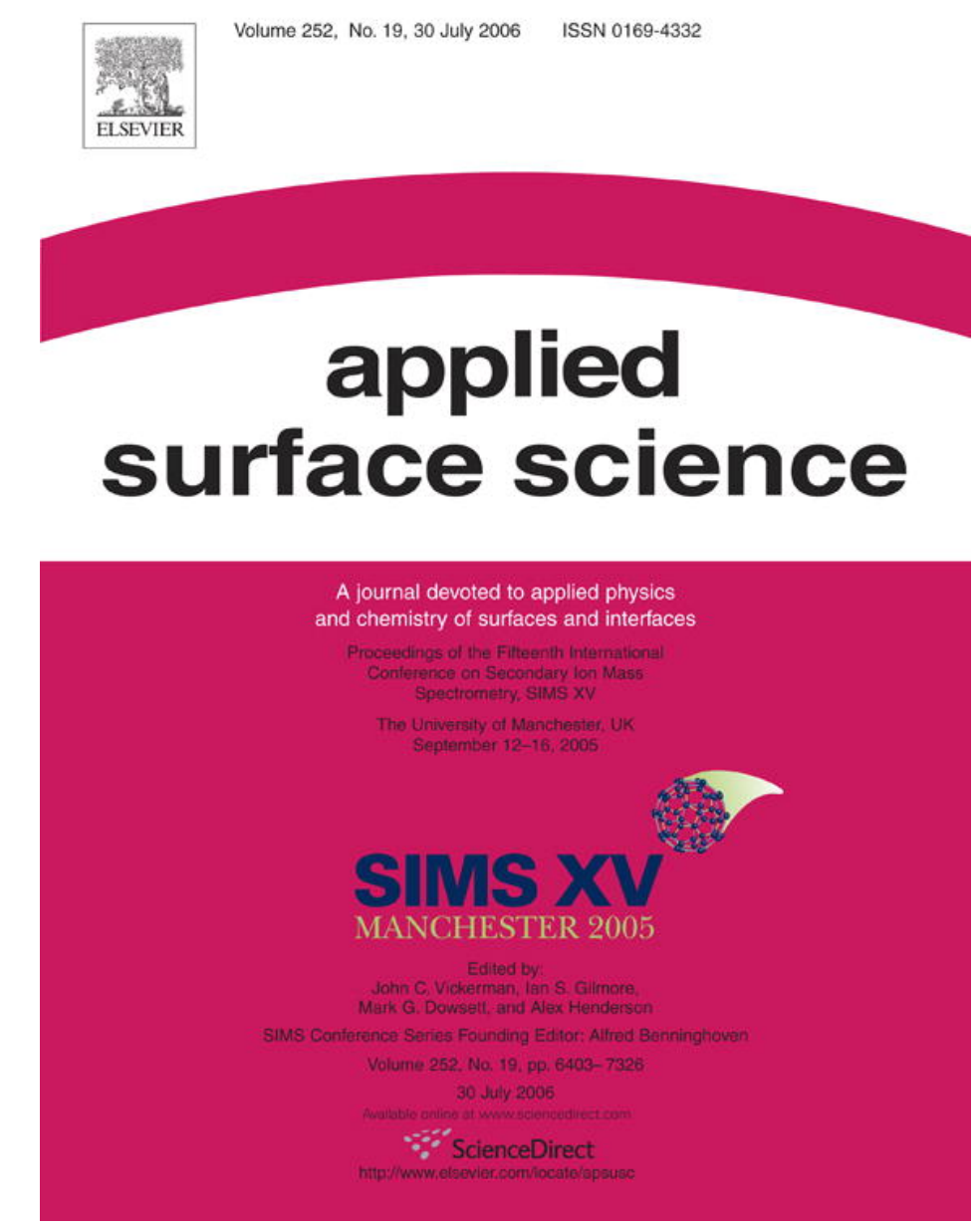

This article was originally published in a journal published by Elsevier, and the attached copy is provided by Elsevier for the author's benefit and for the benefit of the author's institution, for non-commercial research and educational use including without limitation use in instruction at your institution, sending it to specific colleagues that you know, and providing a copy to your institution's administrator.

All other uses, reproduction and distribution, including without limitation commercial reprints, selling or licensing copies or access,

or posting on open internet sites, your personal or institution's website or repository, are prohibited. For exceptions, permission may be sought for such use through Elsevier's permissions site at: 


\title{
Resonant laser-SNMS of boron for analysis of paleoceanographic samples
}

\author{
G. Vering ${ }^{\mathrm{a}}$, C. Crone ${ }^{\mathrm{a}}$, P. Kathers ${ }^{\mathrm{a}}$, J. Bijma ${ }^{\mathrm{b}}$, H.F. Arlinghaus ${ }^{\mathrm{a}, *}$ \\ ${ }^{a}$ Physikalisches Institut, Universität Münster, Wilhelm-Klemm-Str 10, D-48149 Münster, Germany \\ ${ }^{\mathrm{b}}$ Carbon Group, Alfred Wegener Institute for Polar and Marine Research, D-27570 Bremerhaven, Germany \\ Received 12 September 2005; accepted 15 February 2006 \\ Available online 22 May 2006
}

\begin{abstract}
Calcite shells of foraminifera, which are accumulated in the ocean sediment, are an important object of paleoceanographic studies to reconstruct environmental parameters of the past. Foraminifera are unicellular organisms living in almost all parts of the ocean during the entire paleoceanographic time scale. The isotope ratio of boron incorporated in the calcite shell delivers information about the $\mathrm{pH}$-value of the ocean at the time the shell was formed. Since the boron fraction of such a shell is about $5 \mathrm{ppm}$, an extremely sensitive technique is necessary for an exact boron isotope ratio determination. Resonant laser secondary neutral mass spectrometry (r-laser-SNMS) was used to measure boron isotope ratios in calcite shells.

Analysis was carried out with a time-of-flight mass spectrometer equipped with an electron impact gun for sputtering and a Ga ${ }^{+}$primary ion source. Resonant ionization of sputtered boron neutrals was performed via a three-step ionization scheme accomplished with two tunable dye lasers and the fundamental wavelength of a Nd:YAG laser. After optimizing the boron ionization and detection process, boron isotope ratios were directly measured on single foraminiferal shells after removing contaminants by $\mathrm{Ar}^{+}$ion beam sputtering.
\end{abstract}

(C) 2006 Elsevier B.V. All rights reserved.

Keywords: Resonant laser-SNMS; Boron; Isotope ratio; Climate research; Foraminifera; Trace elements

\section{Introduction}

One scientific challenge today is to better understand and quantify the interaction between the atmospheric $\mathrm{CO}_{2}$ budget and the oceanic carbon cycle. The paleo-pH is - among other parameters - important to calculate the oceanic carbonate chemistry. The isotopic composition of boron incorporated in foraminiferal shells is related to the $\mathrm{pH}$-value of the ocean at the time the shell was formed [1].

Foraminifera are unicellular organisms that can be found in every ocean. During their life, foraminifera build a calcite shell in which trace elements from the surrounding water are incorporated. Empty shells accumulate in marine sediments where they build an important ocean archive [2].

In ocean water boron occurs in two compounds: $\mathrm{B}(\mathrm{OH})_{3}$ and $\mathrm{B}(\mathrm{OH})_{4}{ }^{-}$. Their fraction is $\mathrm{pH}$ dependent. The isotopic composition of boron in the ocean is constant along the entire

\footnotetext{
* Corresponding author. +49 251 8339064; fax: +49 2518339063.

E-mail address: arlinghaus@uni-muenster.de (H.F. Arlinghaus).
}

paleoceanographic timescale, but ${ }^{11} \mathrm{~B}$ is enriched in $\mathrm{B}(\mathrm{OH})_{3}$ and ${ }^{10} \mathrm{~B}$ in $\mathrm{B}(\mathrm{OH})_{4}{ }^{-}$because of an isotope change reaction. Therefore, the isotopic composition in these compounds is determined by the $\mathrm{pH}$-value of the water. Only the ionic $\mathrm{B}(\mathrm{OH})_{4}{ }^{-}$is incorporated in foraminiferal shells. Thus, the boron isotope ratio in these shells can be used to reconstruct the $\mathrm{pH}$-value of the ocean [3].

First attempts to measure the isotopic ratio of boron with ToF-SIMS have been previously presented [4]. As the total fraction of boron in the calcite shells is only about $5 \mathrm{ppm}$, an analysis technique with very high sensitivity is needed. The goal of this study is to investigate the potential of resonant laser secondary neutral mass spectrometry (r-laser-SNMS) to measure the isotopic ratio of boron in single foraminiferal shells.

\section{Experimental}

The instrumentation for r-laser-SNMS is based on a time-offlight mass spectrometer (ToF-MS). For analysis a $25 \mathrm{keV}$ liquid metal ion gun $\left(\mathrm{Ga}^{+}\right)$was used. A $10 \mathrm{keV}$ electron impact 
ion gun can be applied for pre-sputtering and depths profiling in dual-beam mode. To avoid interferences between the signals resulting from post-ionized neutrals and secondary ions, pulsed electrical fields on the extraction electrode and the target holder are used to suppress the sputtered secondary ions. The extraction system, consisting of a pulsed extractor and several electrostatic lenses, was optimized to extract a maximum number of post-ionized neutrals out of the ionization volume, defined by the laser beam profile with a diameter of about 1$2 \mathrm{~mm}$. This large ionization volume leads to different starting potentials in the extraction field and thus to a wide energy spread for post-ionized neutrals with the same mass. To correct this, an adapted gridless reflecton-type ToF mass analyzer with high transmission for a wide range of different starting energies was applied. The detection system is comprised of a $10 \mathrm{keV}$ post-acceleration system, a multi-channel plate, a scintillator and a photomultiplier. For signal registration an analog/digital converter (DA 500A from Signatech) is employed.

The laser system consists of two dye lasers pumped by the second harmonic of a Nd:YAG laser. By applying different dyes and different BBO crystals for frequency mixing and doubling, two independently tunable laser beams with wavelengths from 194 to $1036 \mathrm{~nm}$ and the fundamental beam of the Nd:YAG laser $(1064 \mathrm{~nm})$ can be used to perform analyses applying many different resonant ionization schemes.

\section{Results and discussion}

To ionize sputtered boron neutrals resonantly, a three-step ionization scheme was used. The first ionization step begins either at ground state $\left(2 \mathrm{p}^{2} \mathrm{P}_{1 / 2}\right)$ or at a slightly higher level $\left(2 \mathrm{p}^{2} \mathrm{P}_{3 /}\right.$ 2). Both transitions excited by UV laser light with wavelengths of 249.752 and $249.848 \mathrm{~nm}$ reach the same energy level $\left(3 \mathrm{~s}^{2} \mathrm{~S}_{1 / 2}\right)$. The second step requires a visible laser wavelength of 563.484 or $564.864 \mathrm{~nm}$. The second excitation state consists of two different levels $\left(4 \mathrm{p}^{2} \mathrm{P}_{1 / 2}\right.$ and $\left.4 \mathrm{p}^{2} \mathrm{P}_{3 / 2}\right)$; however, measurements showed that the bandwidth of the laser beam is too broad to clearly separate these two states. For the ionization step, the fundamental of the Nd:YAG laser is used. All three excitation steps could be easily saturated with the existing laser system.

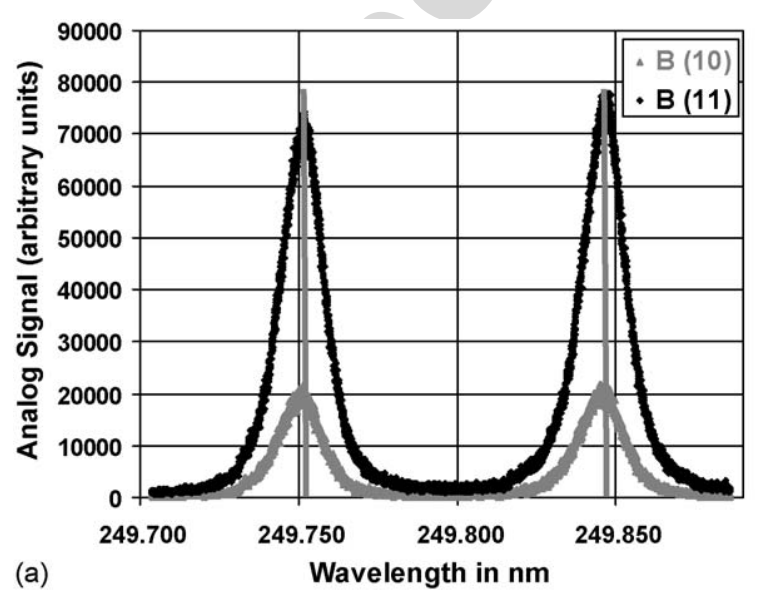

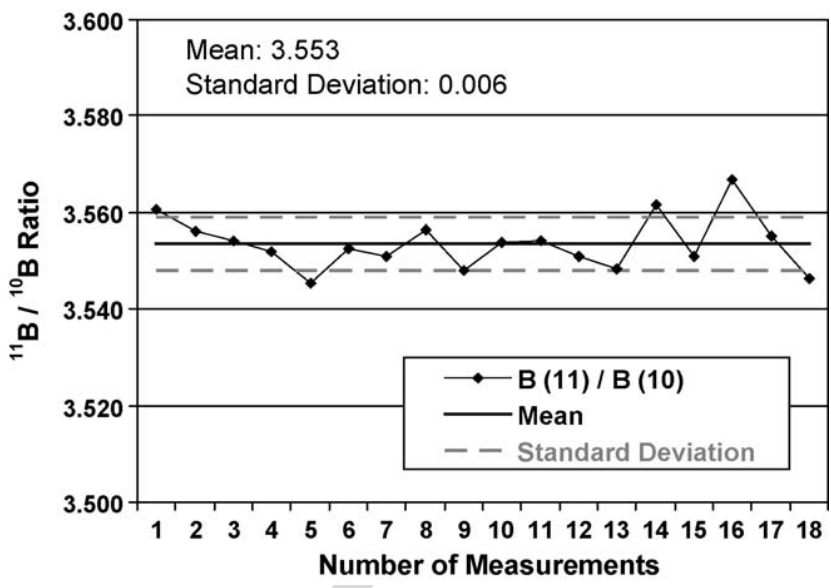

Fig. 2. Consecutive measurements of the boron isotope ratio on a metallic glass sample (analysis time for each data point: $200 \mathrm{~s}$, repetition rate: $50 \mathrm{~Hz}$ ).

Several experiments were performed to investigate the influence of various instrumental parameters on the isotope ratio analysis of sputtered boron neutrals and its reproducibility in general. To get a stable flux of sputtered particles a homogenous metallic glass sample consisting of iron, nickel, boron and molybdenum was used. Stable sputtering conditions could be achieved by bombarding the sample with the $10 \mathrm{keVAr}^{+}$ ion beam rastered over an area of $500 \mu \mathrm{m} \times 500 \mu \mathrm{m}$ for half an hour before and during the analysis using the dual-beam mode.

Fig. 1a shows the signal measured for the two boron isotopes as a function of the laser wavelength used for the first UV excitation step. The two maxima show the two wavelengths, which excite the first step from the ground state $2 \mathrm{p}^{2} \mathrm{P}_{1 / 2}$ and from $2 \mathrm{p}^{2} \mathrm{P}_{3 / 2}$, respectively. The population densities of these two states are almost equal. Thus, it is in principal possible to ionize only approximately half of the sputtered boron neutrals with one UV beam for the first excitation step. A small isotope shift can be observed. It is, however, smaller than 1 pm. Fig. $1 \mathrm{~b}$ shows the signal for the two boron isotopes measured as a function of the laser wavelength used for the second excitation step which goes from the excited state of $3 s^{2} \mathrm{~S}_{1 / 2}$ to either $4 \mathrm{p}^{2} \mathrm{P}_{1 /}$ 2 or $4 \mathrm{p}^{2} \mathrm{P}_{3 / 2}$. These two levels are very close and cannot be

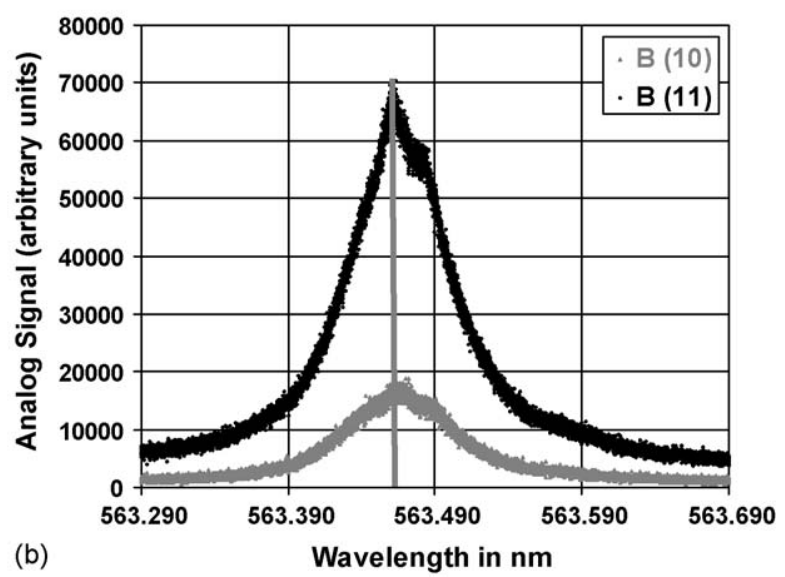

Fig. 1. Laser wavelength scans (a) for the first excitation step and (b) for the second excitation step. 


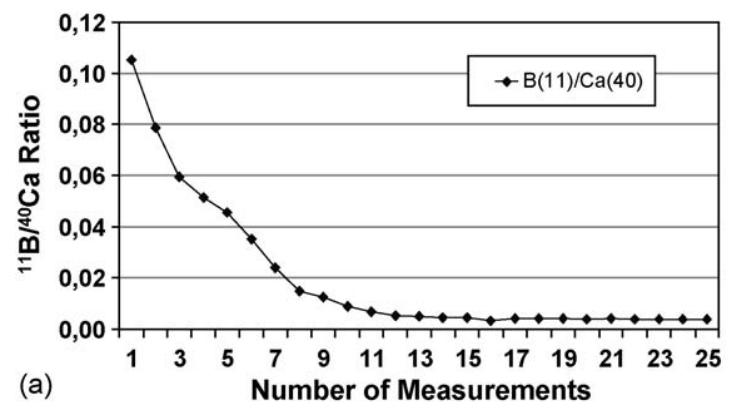

Fig. 3. ${ }^{11} \mathrm{~B} /{ }^{40} \mathrm{Ca}$ ratio directly measured on a calcite shell (a) without pre-sputtering and (b) with pre-sputtering.

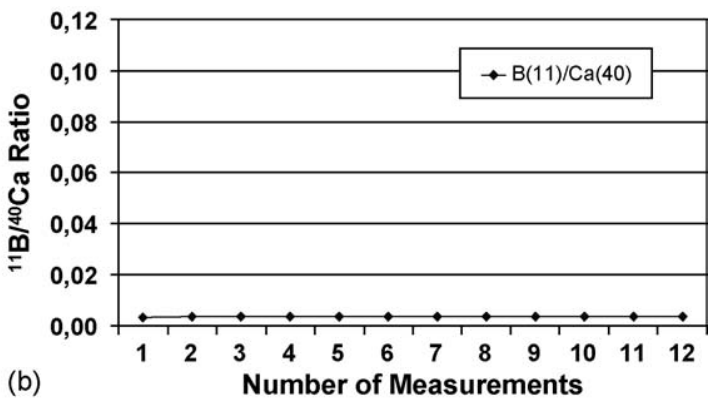

(b) of the untouched calcite shell r-laser-SNMS measurements of boron neutrals were performed. Consecutive measurements were performed, each lasting $600 \mathrm{~s}$ resulting in a primary ion dose density (PIDD) of about $8 \times 10^{14} \mathrm{~cm}^{-2}$. Fig. 3a shows the ${ }^{11} \mathrm{~B} /{ }^{40} \mathrm{Ca}$ ratio. The ${ }^{40} \mathrm{Ca}$ signal results from sputtered, nonresonantly post-ionized calcium atoms. The ${ }^{11} \mathrm{~B} /{ }^{40} \mathrm{Ca}$ ratio decreases at the beginning and reaches a stable ratio at a level of 0.005 after approximately 14 measurements. The decrease of the ratio can be explained by surface contaminants, which were removed by the increasing primary ion dose. A second experiment confirms this observation. For this experiment the surface was sputter-cleaned with a high ion dose $\left(\mathrm{dc}^{+}{ }^{+}\right.$ion sputtering for $30 \mathrm{~min}$, PIDD: approximately $5 \times 10^{16} \mathrm{~cm}^{-2}$ ) before analysis. Fig. $3 \mathrm{~b}$ shows the obtained data. Immediately at the beginning of the measurements the same ${ }^{11} \mathrm{~B} /{ }^{40} \mathrm{Ca}$ ratio could be obtained, which was reached without pre-sputtering (Fig. 3a) after 14 measurements. This demonstrates that with ion pre-sputtering direct boron isotope ratio measurements in the inner part of a single foraminifera shell should be possible.

Fig. 4 represents the first r-laser-SNMS isotope ratio measurements obtained from a single foraminifera shell after pre-sputtering (PIDD: approximately $9 \times 10^{16} \mathrm{~cm}^{-2}$ ). The differences in the absolute isotope ratio compared to the measurements obtained on the metallic glass sample (Fig. 4) were caused by different voltage settings for the detection system. The measured boron signal intensity is very low because the boron concentration is only in the low ppm range. Thus, the variation of the measured isotope ratios is mainly a function of counting statistics.

\section{Conclusion}

High precision boron isotope ratio analysis was investigated on metallic glass samples using r-laser-SNMS. It was possible to perform consecutive measurements with a standard deviation in the range of only a few per mil. First r-laser-SNMS boron isotope ratio measurements have been performed on a single foraminiferal calcite shell. It was found that intensive pre-sputtering is required for removing contamination and to reach stable analysis conditions. As the measured isotope ratio depends strongly on instrumental parameters, well-known standard samples have to be used for calibration. The data show that it is in principal possible to measure boron isotope ratios on single foraminiferal shells. However, the number of detectable neutrals per unit time must be significantly increased to reach the accuracy needed for
Fig. 4. Consecutive measurements of boron isotope ratio on a foraminiferal shell after pre-sputtering (analysis time for each data point: $200 \mathrm{~s}$, repetition rate: $50 \mathrm{~Hz}$ ). 
paleo-pH reconstruction. This could be achieved by increasing the repetition rate of the measurement cycles and/or by using primary ion guns with very high ion currents in order to enhance the number of sputtered particles per shot.

\section{Acknowledgements}

This work was financially supported by the European Community under Contract No. EVK2-CT-2002-00135 6C and by the Deutsche Forschungsgemeinschaft.

\section{References}

[1] G. Wefer, W.H. Berger, J. Bjima, G. Fischer, Use of Proxies in Paleoceanography: Examples From the South Atlantic, Springer, Berlin, 1999, pp. $1-68$.

[2] D.W. Lea, in: B.K. Sen Guppta (Ed.), Modern Foraminifera, Kluwer Academic Publishers, London, 1999, pp. 259-277.

[3] N.G. Hemming, G.N. Hanson, Geochim. Cosmochim. Acta 56 (1992) $537-$ 543.

[4] G. Vering, C. Crone, J. Bijma, H.F. Arlinghaus, Appl. Surf. Sci. 203-204 (2003) 785-788. 